\title{
Consumer Tax Production Quota Buyouts and Negative Compensation: Producers' Dilemma
}

\author{
Andrew Schmitz ${ }^{1}$, Dwayne J. Haynes ${ }^{1}$, Troy G. Schmitz ${ }^{2}$ \\ ${ }^{1}$ Food and Resource Economics, Institute of Food and Agricultural Sciences, University of Florida, Gainesville, USA \\ ${ }^{2}$ Morrison School of Agribusiness and Resource Management, Arizona State University, Mesa, USA \\ Email: aschmitz@ufl.edu,nygator3@ufl.edu,troy.schmitz@asu.edu
}

Received February 1, 2013; revised March 19, 2013; accepted April 19, 2013

Copyright (c) 2013 Andrew Schmitz et al. This is an open access article distributed under the Creative Commons Attribution License, which permits unrestricted use, distribution, and reproduction in any medium, provided the original work is properly cited.

\begin{abstract}
In some cases, production quota buyouts can be paid for through consumer taxes. Using a simplified two-period model, we show that producers can never gain from a consumer tax buyout even if the compensation is based on an inflated quota value. The higher the quota value used as the basis of compensation, the greater is the overall producer loss from the buyout. This producer loss within a two-period model buyout is called "negative producer compensation".
\end{abstract}

Keywords: Consumer Tax Production Quota Buyout; Negative Compensation; Tobacco

\section{Introduction}

Production quotas have been in existence for quite some time. In the United States, for example, many production quota programs were put into place in the 1930s. Since then, several of these programs have been eliminated. Examples include the US peanut and tobacco programs, which ended in 2002 and 2004, respectively, accompanied by compensation to producers. In the tobacco program buyout, producers were compensated for the loss of their quota with funds generated from the introduction of a consumer tobacco tax. This was not the case for peanuts, for example, as compensation came from the US Treasury. We show that in a two-period case, producers can never gain from a consumer tax buyout even if the compensation were based on an inflated quota value. The higher the quota value used as the basis of compensation, the higher is the overall producer loss from the buyout. This producer loss within a simple two-period model production quota buyout is called "negative producer compensation”.

\section{Quota Implementation}

Consider the model in Figure 1 where $S$ is the supply schedule and $D$ is the demand schedule. The competitive price is $p_{0}$ and the corresponding output is $q_{0}$. By introducing a production quota $q_{1}$, the price increases to $p_{1}$, and as a result, consumers lose $\left(p_{1} p_{0} b a\right)$. Producers gain $\left[\left(p_{1} p_{0} d a\right)-(d c b)\right]$ and now receive the true value of the quota $\left(p_{1} p_{2} c a\right)$ from market [1,2]. The deadweight loss created by the quota is $(a c b)$ [3].

\section{Quota Removal}

Little is known about the removal of production quotas, especially when consumer taxes are used as a basis of compensation. We now consider two cases. In the first case, producers are compensated based on the true quota value. In the second case, producers are compensated based on an inflated quota value [4].

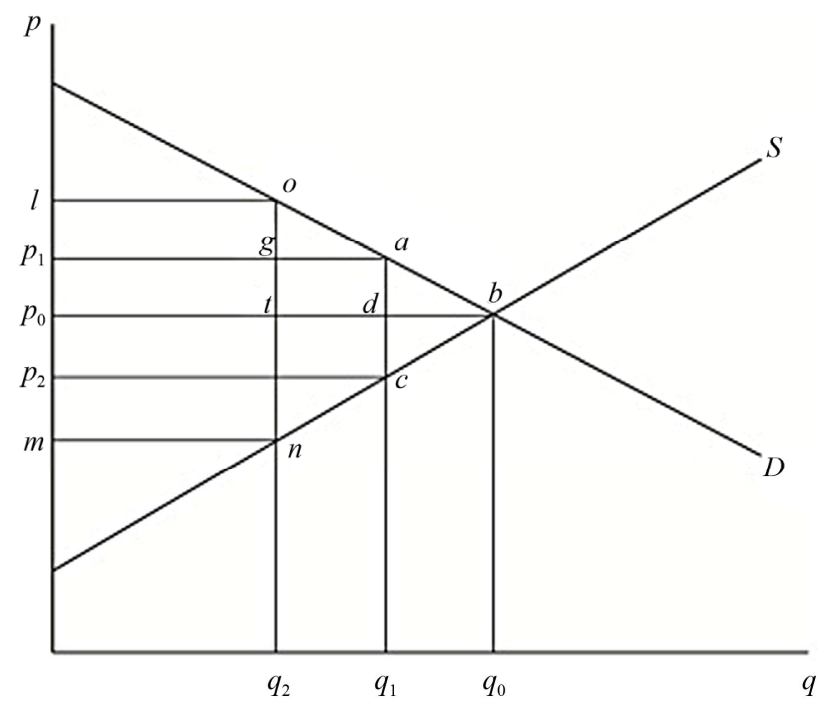

Figure 1. Theoretical consumer tax buyout. 


\subsection{True Quota Value}

In a two-period case, consider the effect of buying out the quota and using a consumer tax to pay for producer compensation (Figure 1). In the first period of the buyout (in the case where the consumer tax exactly equals the value of the quota), there is no gain to producers. In the second period, the consumer tax is removed, competitive equilibrium is restored and the negative producer compensation is $\left[-\left(p_{1} p_{0} d a\right)+(d c b)\right]$. As can be seen from Section 2 above, this loss is equal to the dollar area that was gained from the quota being implemented.

\subsection{Inflated Quota Value}

There have been cases [4] where production quotas have been ended where producers, through rent-seeking activities, were able to persuade politicians to pay compensation on the basis of a quota value that exceeds the true value of the quota. Note that the value of the quota increases beyond the true value since $\left[(\right.$ Imno $\left.)>\left(p_{1} p_{2} C a\right)\right]$. What happens if an inflated quota value is used as the basis of compensation in a consumer tax buyout of only two periods? Producers are actually worse off (Figure 1). While they do gain $\left[\left(l p_{1} g o\right)-(g n c a)\right]$ in the first period, producers lose an even larger area of $\left[\left(l_{0} t o\right)-(t n b)\right]$ when competitive equilibrium is restored in the second period. Even in the case of an inflated quota buyout, there is still a net loss to producers given a two-period model. In effect, under this scenario, the larger the consumption tax is, the greater the producer losses (i.e., negative producer compensation).

\subsection{Varying Demand Elasticities}

What would be the effect of the buyout on producers under different demand price elasticities? We present extreme cases of both elastic and inelastic demands.

\subsubsection{Elastic Demand}

Consider Figure 2 where a theoretical consumer tax buyout under elastic demand conditions is depicted. In period one, the impact on producers from the inflated quota buyout is $\left[\left(l p_{1} g o\right)-(\right.$ gnca $\left.)\right]$. Thus in period one, there is a negative gain to producers from accepting the inflated consumer tax buyout. Also, producers in period two lose $\left[-\left(l p_{0} t o\right)+(t n b)\right]$ when competitive equilibrium is restored. Thus, over the two periods, the net loss to producers from the quota buyout totals $\left[\left(l_{1} g o\right)-(\right.$ gnca $\left.)\right]$ $+\left[-\left(l p_{0} t o\right)+(t n b)\right]$.

\subsubsection{Inelastic Demand}

Now consider Figure 3 where a theoretical consumer tax buyout under inelastic demand conditions is depicted. This case is considerably different from the previous one

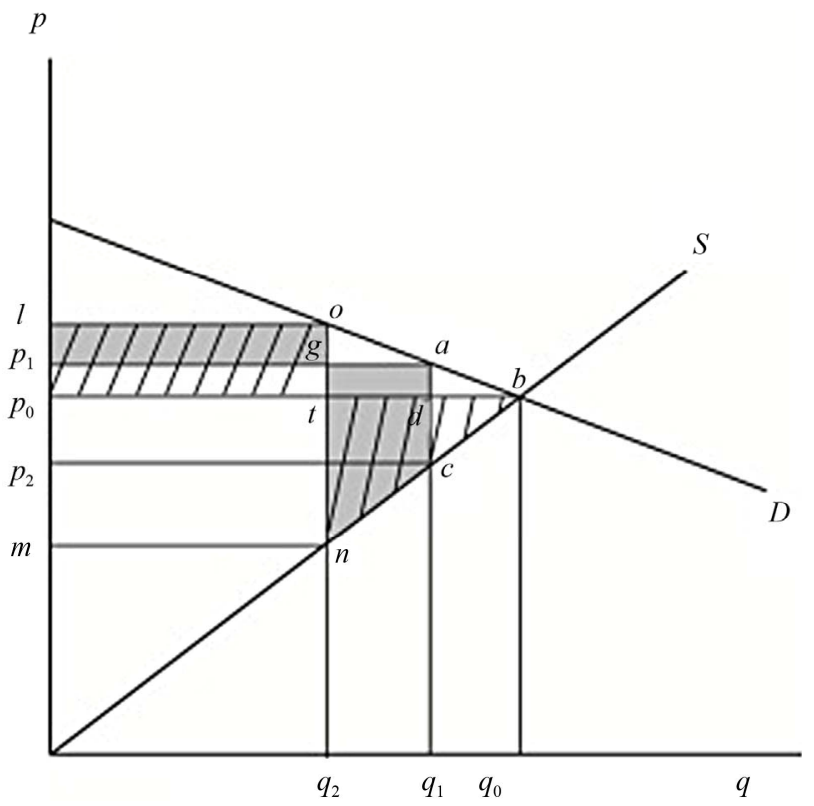

Figure 2. Theoretical consumer tax buyout: Elastic demand.

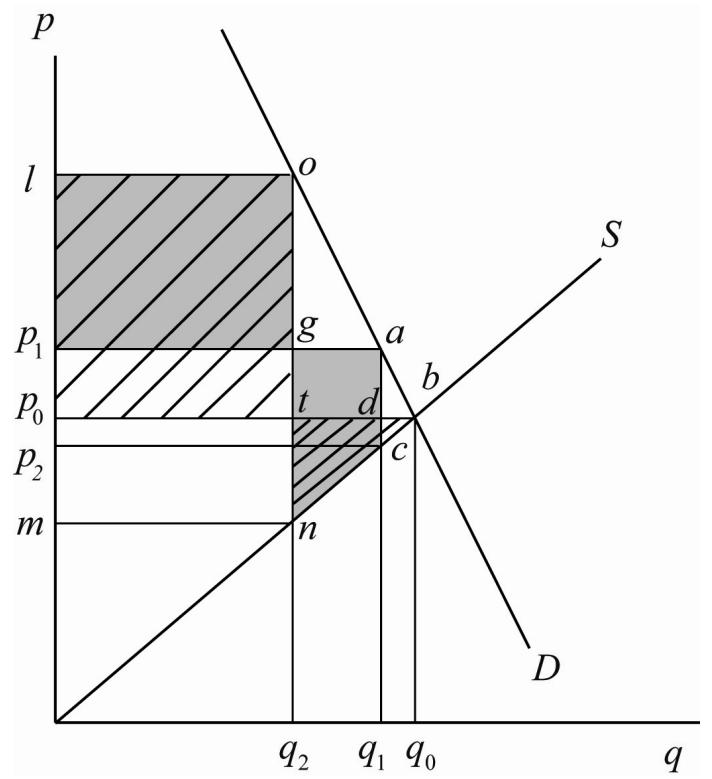

Figure 3. Theoretical consumer tax buyout: Inelastic demand.

regarding both periods one and two.

In the first period, unlike the elastic demand case above, producers, on net, gain $\left[\left(l p_{1} g o\right)-(g n c a)\right]$ from the buyout. However, in the second period, there is a producer loss of $\left[\left(l p_{0} t o\right)-(t n b)\right]$ from restoring competitive equilibrium. This loss is significantly larger than the gain in the first period. It is also larger than the second period loss under elastic demand conditions. In total, producers' net loss from the buyout is $\left[\left(l p_{1} g o\right)-(g n c a)\right]+\left[\left(l p_{0} t o\right)-\right.$ (tnb)]. Thus:

1) The more elastic the demand conditions, ceteris 
paribus, the greater is the possibility in period one that producers will lose from the buyout.

2) Given elastic demand conditions, ceteris paribus, the smaller are the losses over the two periods from the restoration of competitive equilibrium.

3) The more inelastic the demand conditions, ceteris paribus, the greater are the gains in period one to producers from the buyout.

4) Given inelastic demand conditions, ceteris paribus, the greater are the producer losses in period two from the restoration of competitive equilibrium.

5) On net, given elastic demand conditions, there is "negative producer compensation" from a consumer tax buyout.

6) On net, given inelastic demand conditions, there also is "negative producer compensation" from a consumer tax buyout.

\section{Concluding Remarks}

Given a consumer tax buyout of production quotas, in a simple two-period model, producers will always lose from the termination of a production quota program. In the first-period of a two-period model, producers may gain or lose from the consumer tax buyout. This is also the case in the second period. However, when both periods are taken together, there is a net loss to producers from a consumption tax compensation buyout. In further research, one should develop a multi-period model incorporating discounting.

\section{REFERENCES}

[1] A. Schmitz and T. G. Schmitz, "Benefit-Cost Analysis: Distributional Considerations under Producer Quota Buyouts," Journal of Benefit-Cost Analysis, Vol. 1, No. 2, 2010, Article 2. http://www.bepress.com/jbca/vol1/iss1/2

[2] T. G. Schmitz and A. Schmitz, "Compensation and the Twin Producer Gains from Production Quotas,” Theoretical Economic Letters, Vol. 1, No. 3, 2011, pp. 70-72. doi:10.4236/tel.2011.13015

[3] R. Just, D. Hueth and A. Schmitz, "Applied Welfare Economics and Public Policy,” 2nd Edition, Prentice-Hall Publishers, Englewood Cliffs, 2004.

[4] T. G. Schmitz, A. Schmitz and D. Haynes, "Inflated Production Quota Gains Paid for by a Consumption Tax," Theoretical Economic Letters, Vol. 2, No. 1, 2012, pp. 67-68. doi:10.4236/tel.2012.21012 